\title{
MARÍA INÉS SARAVIA y CRISTINA A. FEATHERSTON (Eds.). Expresiones de violencia en la literatura. De Grecia a nuestros días. FaHCE, La Plata, 2019, 259 pp.
}

\author{
Vega del Pino, Gloria \\ MARÍA INÉS SARAVIA y CRISTINA A. FEATHERSTON (Eds.). Expresiones de violencia en la literatura. De \\ Grecia a nuestros días. FaHCE, La Plata, 2019, 259 pp. \\ Synthesis, vol. 26, núm. 2, 2019 \\ Universidad Nacional de La Plata, Argentina \\ Disponible en: http://www.redalyc.org/articulo.oa?id=84662943009 \\ DOI: https://doi.org/10.24215/1851779Xe066
}

Esta obra está bajo una Licencia Creative Commons Atribución-NoComercial-Compartirlgual 4.0 Internacional 


\section{MARÍA INÉS SARAVIA y CRISTINA A. FEATHERSTON (Eds.). Expresiones} de violencia en la literatura. De Grecia a nuestros días. FaHCE, La Plata, 2019, 259

pp.

Gloria Vega del Pino

Universidad de La Laguna, España
DOI: https://doi.org/10.24215/1851779Xe066

Redalyc: http://www.redalyc.org/articulo.oa?id=84662943009

Saravia María Inés, Featherston Cristina A.. Expresiones de violencia en la literatura. De Grecia a nuestros días. 2019. La Plata. FaHCE.

$259 \mathrm{pp}$.

Este libro es un ensayo que trata el tema de la violencia manifiesta a través de la literatura. Compuesta por una introducción y siete artículos científicos, es una obra genuina en el campo de la investigación.

El primer artículo, de Saravia, titulado "La poética de la gloria y del dolor en Electra, de Sófocles", resulta un trabajo magistral sobre la obra teatral desde el punto de vista filológico y psicológico. Su detenimiento en el sentido y la estructura de los términos griegos y de la estructura teatral manifiestan un profundo conocimiento del griego y transporta a las personas lectoras a la propia mente de Sófocles. A pesar de la continua referencia al griego, el texto cuenta con la traducción y hace posible que todo aquel interesado en la lectura pueda entender y reflexionar sobre el tema en cuestión: la violencia y el dolor. Otras ideas que suscita este análisis científico de la obra son: la muerte lejos de la patria, la necesidad humana y familiar de honrar a los muertos, los combates internos ante la muerte y el futuro truncado y la literatura como medio de expresión de nuestra realidad humana, entre otros.

Cuando se habla de la guerra, en general, a la mente del oyente suele venir un concepto abstracto, cruento, pero genérico y que afecta a todas las personas en la misma medida. Hamamé ha sido capaz de poner en su lugar la tragedia Suplicantes, tan desprestigiada, justificando con argumentos el magnífico ingenio poético en cuanto a la estructura y a todas las innovaciones euripideas. Asimismo, hace hincapié, en el capítulo “Suplicantes, de Eurípides: una representación de la violencia extrema de la guerra” en la necesidad de Eurípides de mostrar la dualidad entre sociedad e individuo frente a la violencia. El deseo del dramaturgo de suscitar reflexiones en su público se traspasa a este artículo, que a su vez nos genera preguntas del tipo: ¿no es acaso la violencia una experiencia individual?, ¿no merecen los sufrientes manifestar sus sentimientos a fin de reflexionar sobre la capacidad violenta del ser humano?

Reflexionar sobre el cambio es lo que nos enlaza con el siguiente artículo, "La violencia implícita hacia el Otro: paternalismo y esclavitud en los poemas homéricos”, de Álvarez Rodríguez. Esta investigadora se posiciona en el estudio de la esclavitud en las obras literarias originarias de nuestra cultura: la Ilíada y la Odisea. ¿Quién es esta gente y cómo se la trata?, ¿quién y cómo se llega a esta condición no humana? Es inquietante ver cómo esta autora pone a los lectores y lectoras contra las cuerdas de su propia ética. El mundo clásico es un espejo que muchas veces muestra aspectos admirables de la cultura, pero también su lado oscuro. Muchas aberraciones nos han hecho llegar aquí, pero en la actualidad es necesaria la autocrítica personal y social: ¿justifico la esclavitud? ¿Qué pasa con los esclavos que hoy día siguen siendo no humanos? Descubre en este artículo los autoengaños heredados desde Homero.

Puede ser muy frecuente dentro del pensamiento humano creer que el contenido clásico está ya anticuado, que no responde a las necesidades de nuestra sociedad. Sin embargo, Delbueno nos lo ha desmentido. La comparativa entre la obra teatral de Eurípides y Grillparzer pone de relieve el potencial que tiene Medea. Ya lo hizo Eurípides, a su manera, saltándose los cánones clásicos, poniendo a una mujer como protagonista en la 
escena, y Grillparzer la retomó acercándonos aún más la violencia a la que estaba sometida como mujer, como extranjera, como no griega y de costumbres profanas. Delbueno hila muy bien este recorrido comparativo entre las obras y expone fácilmente la complejidad que envuelve a Medea haciendo hincapié en el profundo carácter violento con el que Grillparzer retoma a este personaje mítico. La violencia externa e interna, así como el concepto de justicia, divina y humana, son algunos de los grandes temas que la autora trata en este artículo.

Por otro lado, Gowland analiza en su artículo"La percepción y la representación del amor y de la guerra en Antonement, de Ian McEwan"uno de los clichés acérrimos de la literatura y de la vida: "en el amor y en la guerra todo vale". A través del estudio de la obra Antonement y su posterior síntesis, en este artículo, Gowland ofrece la posibilidad de que la persona lectora recuerde o descubra que la percepción de la realidad y los sentimientos que surgen hacia algo siempre están ligados a la propia experiencia personal. ¿Cuáles son las experiencias que llevan a Briony a concebir el amor y la guerra como ambas caras de la misma violencia? Gowland es capaz de acompañarnos y desvelarnos cómo son las experiencias de la protagonista y narradora de esta obra. Es capaz de acercarnos y hacernos entender que Briony no puede cambiar esta idea porque su propia experiencia es violenta: la información que recibe de su familia, que configura su personalidad, así como sus propios actos son los que la han llevado a ese estado.

En correlación con el tema, Pascual nos ofrece un estudio detallado sobre la obra The heather Blazing. La normalización de la violencia en la vida diaria, la violencia ejercida sobre las mujeres y la historia bélica del país son los tres ejes violentos sobre los que se ve envuelto el protagonista de la obra: un juez. La concepción de una Irlanda idealizada en la que se mueve la mayoría de la sociedad, unida a la tensión que vive tanto en el ámbito público como en el privado, es lo que suscita esta pregunta: ¿cómo se puede afrontar tanta violencia? Es quizás lo que no cuenta el protagonista lo que permite que todo aquel que lea el artículo de Pascual se pregunte: ¿cuál es mi actitud ante la violencia que me rodea? ¿ $\mathrm{O}$ es que no existe?

Por último, Featherston, en "Las letras sobre las guerras: Necesidad y límites de una relación conflictiva en tres novelas contemporáneas", ha hecho un trabajo titánico al comparar en las tres novelas la violencia que de ellas se desprende: Adiós a las armas, Mrs Dalleway y El paciente inglés. ¿Qué siente un humano frente a la violencia de la guerra?, ¿cómo se puede abandonar esa experiencia? Featherston recoge de manera muy sintética la problemática de cada obra y es imposible que el lector o lectora no respalde este estudio, ya sea por un proceso de empatía hacia los personajes de la obra o porque la contextualización de las obras (la II Guerra Mundial) aún está muy reciente en la memoria social. Mientras que Adiós a las armas demuestra el aleccionamiento de la guerra en cada personaje y la imposibilidad de vivir al margen de este hecho, Featherston destaca la imposibilidad o la negativa voluntaria del protagonista a expresar su propia experiencia; Mrs Dalleway recoge la necesidad del autoengaño de la propia sociedad que finge el final de la guerra, pero que se aterra ante el suicidio de aquellos que solo pueden hacer frente a la experiencia violenta de la guerra a través de la muerte. Curiosamente, esta investigadora ha puesto al final la comparativa de la obra El paciente inglés, ya que, a pesar de continuar con la violencia de la guerra, es la única obra de estas tres que presenta una esperanza de superar las experiencias violentas que el conflicto ha tenido con cada personaje.

Sin duda alguna, es un compendio de artículos especializados y al mismo tiempo accesible, que no dejará indiferente a las personas lectoras, además de animar a otros investigadores e investigadoras a continuar con el estudio de la violencia expresada en la literatura.

CC BY-NC-SA 